\title{
Investigando Saberes Docentes sobre Avaliação Educacional: ação e pesquisa
}

\author{
MARLI ANDRÉ \\ Professora do Programa de Estudos Pós-graduados em Educação: \\ Psicologia da Educação da PUC-SP \\ marliandre@pucsp.br
}

\begin{abstract}
Resumo
O presente texto busca mostrar mudanças nos saberes sobre avaliação educacional de professoras da rede estadual paulista que participaram de um processo de formação continuada nos anos de 1997-1998. Além disso, discute questões e desafios enfrentados no desenvolvimento da pesquisa-ação.

Palavras-chave: estudo de caso, avaliação qualitativa, formação docente, concepções de avaliação, pesquisa-ação.
\end{abstract}

\section{Resumen}

Este artículo intenta demostrar la evolución de los conocimientos sobre la evaluación educativa en el profesorado de la red estatal de São Paulo que fueron partícipes de un proceso de formación continua en el periodo 97-98. Además, discurre sobre cuestiones y desafíos enfrentados en el desarrollo de la investigación-acción.

Palabras-clave: estudios de caso, evaluación cualitativa, formación docente, concepciones de evaluación, investigación-acción.

\begin{abstract}
This paper tries to show changes in educational evaluation conceptions of a group of teachers involved in an in-service teacher education program between 1997 and 1998 in the city of São Paulo. It also discusses many issues and challenges one faces in the process of conducting action research.

Key words: case study, qualitative evaluation, teacher training, evaluation concepts, actionresearch
\end{abstract}




\section{INTRODUÇÃO}

A proposta deste texto é discutir resultados e questões emergentes de uma investigação dos saberes docentes sobre avaliação educacional.

Inicialmente, faz-se necessário explicitar o contexto da investigação. Trata-se de um projeto que buscou desenvolver, com professoras das séries iniciais do ensino fundamental, uma metodologia de leitura crítica da sua prática docente. Os dados foram coletados quando da realização de um processo de formação continuada que fez parte do convênio entre a Secretaria Estadual de Educação de São Paulo e a Faculdade de Educação da Universidade de São Paulo (SEESP/FEUSP) nos anos de 97 e 98. Atuei como professora formadora de um grupo de 32 professoras de $1^{\mathrm{a}}$ a $4^{\mathrm{a}}$ série provenientes de 9 escolas da rede estadual paulista.

O Projeto de Educação Continuada da SEESP dava total liberdade às universidades para a proposição de temas e metodologias. A Faculdade de Educação da USP acolheu as propostas dos docentes interessados em participar do Projeto e as divulgou nas Delegacias de Ensino. No caso aqui apresentado foi anunciado que o curso "Professor Leitor Crítico de sua Prática" objetivava desenvolver, com as professoras, uma metodologia de leitura crítica da sua prática docente que levasse a uma reflexão e a uma mudança nas práticas de leitura/escrita e de avaliação na sala de aula.

Inscreveram-se no curso os professores interessados nessa proposta. Como o grupo de inscritos era grande, nós o dividimos em duas turmas de aproximadamente 30 professoras, tendo uma turma ficado sob a coordenação da professora Mary Júlia Dietzsch, que tratou mais diretamente do tema da leitura/escrita e a outra, sob minha responsabilidade, trabalhou com o tópico da avaliação educacional.

O presente texto discute questões relativas ao processo de investigação dos saberes dessas professoras sobre avaliação, e se centra mais especificamente nos desafios metodólogicos encontrados ao se desenvolver uma pesquisa-ação.

\section{O PROCESSO DE FORMAÇÃO CONTINUADA}

Fundamentada na literatura recente sobre formação docente e em especial nos estudos sobre formação continuada, que enfatizam a importância da reflexão e a valorização dos saberes docentes (entre outros autores: Nóvoa, 1992; Zeichner, 1992; Pérez Gómez, 1992; Gimeno Sacristán, 1991; Perrenoud, 1993; Tardif, 2002), a proposta do curso 
estruturou-se em torno de alguns princípios que definiram a metodologia de trabalho. Os princípios podem ser assim resumidos:

a) desenvolvimento profissional através da tomada de consciência acerca do próprio processo de aprendizagem e reflexão distanciada sobre a prática docente - uso do diário reflexivo;

b) formação do professor leitor/escritor - uso de textos literários, música, escrita e reescrita de textos pessoais;

c) participação na construção coletiva de conhecimentos - uso do seminário como espaço coletivo de troca de saberes;

d) desenvolvimento da autonomia intelectual - elaboração e implementação de projetos em sala de aula - instrumentos de mudança da prática docente.

A metodologia consistiu em encontros sistemáticos quinzenais de duas pesquisadoras ${ }^{1}$ com os professoras, com duração de quatro horas, estendendo-se pelo período de dois anos. Nesses encontros, que se caracterizaram como os seminários propostos por Barthes (1987), as professoras estudavam, discutiam coletivamente suas práticas de sala de aula, analisavam conjuntamente seus diários reflexivos, elaboravam projetos de intervenção e os implementavam em suas classes, escreviam e reescreviam textos.

\section{AÇÃO FORMADORA E SUA INVESTIGAÇÃO}

Uma questão bastante importante para os que desenvolvem processos de formação continuada, e especialmente para os que buscam investigar sua efetividade, é como medir os resultados, ou seja, como determinar se as mudanças ocorridas foram fruto do processo vivido pelos docentes. Como posso saber quais foram os resultados e se foram (ou não) positivos?

Preocupadas com essas questões buscamos coletar dados, em diversos momentos do trabalho de formação, para tentar detectar o possível impacto do projeto.

Se um dos objetivos da ação formadora era levar as professoras a utilizarem práticas de avaliação voltadas para o sucesso dos alunos, a investigação pretendia verificar em que medida esse objetivo havia sido alcançado. Assim, seria necessário identificar as concepções e práticas de avaliação das professoras no início do processo e retomá-las, novamente,

${ }^{1}$ Essa pesquisa contou com a colaboração da pesquisadora Marta Darsie, da UFMT. 
no final, para compará-las e determinar os ganhos obtidos. A ação formadora também exigia uma medida no meio do processo, para verificar se os métodos, as estratégias e os conteúdos da formação continuada estavam atendendo aos interesses das professoras e o que seria preciso melhorar em razão dos objetivos pretendidos.

Além da análise dos diários reflexivos, que foram usados para registro das aprendizagens das professoras e das mudanças efetuadas em suas salas de aula, utilizamos a estratégia de escrita e reescrita de textos.

No primeiro dia dos seminários, solicitamos às professoras que elaborassem um pequeno texto com o seguinte enunciado: "o que significa para mim a avaliação?". Explicamos que o objetivo da atividade era registrar o que elas já sabiam sobre avaliação e que retomaríamos esses registros no final do curso. Utilizamos, ainda, uma dinâmica de grupo, através da técnica do GV/GO - grupo de verbalização-observação - em que solicitamos que relatassem as práticas avaliativas utilizadas em seu trabalho cotidiano. Uma observadora anotou as falas das professoras no nosso diário de campo. Com isso, pudemos ter os registros para a pesquisa e os dados para planejar as atividades e selecionar o material de apoio do primeiro módulo semestral.

\section{ANÁliSE DAS CONCEPÇÕES DE AVALIAÇÃO NO INÍCIO DO PROCESSO}

Uma análise de conteúdo dos 32 textos elaborados pelas professoras no primeiro momento do curso mostrou que:

\section{a) quase a metade do grupo (13 ou $41 \%$ ) considerava a avaliação como uma forma de aferir (medir) o conteúdo}

A seguir estão alguns exemplos mais significativos dessa concepção, seguidos pela identificação do sujeito-professor (S):

“É um meio para medir conhecimento." (S32)

"É um processo onde se faz análise dos conteúdos estudados e absorvidos pelos alunos." (S27)

"O que a criança conseguiu assimilar do conhecimento dado." (S8 e S28)

"Se o conteúdo está sendo aceito e aprendido." (S11)

"É uma maneira saudável e descontraída de verificar se o que eu quis passar para os meus alunos foi assimilado." (S16)

"Uma maneira de rever os conteúdos a serem trabalhados novamente." (S29) 
Nessas afirmações, fica evidente não apenas a preocupação exclusiva com a medida dos conteúdos, mas revelam também uma concepção de ensino fundada na transmissão de conhecimento, e uma concepção de aprendizagem como assimilação do conteúdo "passado" pelo professor.

b) seis respondentes enfatizavam a avaliação como investigação didática

"É o ponto de partida para verificar como está a minha prática pedagógica." (S26)

"Permite buscar o fio condutor do nosso trabalho, repensando o que deu certo e o que precisa ser reestruturado." (S10)

"É um processo contínuo, onde repenso minha prática, reflito e replanejo minhas ações." (S30)

Percebe-se, nessas afirmações, que algumas professoras manifestavam, já no início do curso, uma preocupação em usar as informações colhidas pela avaliação para repensar o ensino, ou seja, a sua própria prática.

\section{c) duas professoras associaram a avaliação ao medo}

"Continuo sentindo insegurança e medo de errar." (S4)

"Significa para mim, às vezes, um terror." (S18)

É muito comum associar a avaliação a sentimentos negativos como medo, terror, insegurança. O que parece interessante é que ao registrarem em seus textos e, posteriormante, trazerem para a discussão coletiva esses sentimentos essas professoras permitiram que o grupo relacionasse tais emoções com as que os alunos experimentam nas situações escolares.

\section{d) duas professoras ressaltaram o caráter contínuo e diagnóstico da avaliação}

"É o trabalho diário dos meus alunos." (S15)

"É contínua, diária e diagnostica se o aluno está aprendendo." (S12)

Fica evidente, nessas afirmações, que algumas professoras já haviam incorporado, em seu discurso, os princípios da avaliação formativa. 

e) duas professoras mostraram uma percepção muito genérica da avaliação

"Avaliar é o despertar do aluno." (S13)

"Se o aluno conseguiu aprender." (S14)

\title{
f) uma professora enfatizou o aspecto quantitativo da avaliação
}

"Testar a capacidade de realizar uma prova com um número razoável de acertos." (S1)

\section{g) uma professora associou a avaliação com trabalho e reflexão}

\begin{abstract}
"Significa trabalho para quem é aluno e instrumento para quem é professor. Para o professor, avaliação deveria ser um instrumento diário para produzir trabalho, mas trabalho reflexivo." (S5)
\end{abstract}

\section{h) uma professora viu na avaliação um mecanismo de poder}

"O mais difícil não é ser avaliado, mas avaliar, pois as relações de poder que se escondem por trás dessa ação podem gerar gratidão ou trauma para o resto da vida." (S22)

O que fazer diante de saberes tão heterogêneos e plurais? Reconhecê-los? Revelá-los? Respeitá-los?

Pensando na ação formadora, essas concepções poderiam/deveriam ter sido devolvidas imediatamente ao grupo, analisadas, discutidas, até mesmo para evidenciar a sua pluralidade e para fazer desse exemplo um ponto de partida para refletir sobre as diferenças que estão presentes em uma sala de aula e a importância de levá-las em conta. Mas, naquele momento, não havia essa clareza, pois havia uma grande preocupação com a pesquisa sobre a formação. Pretendia-se reservar os textos das professoras para mais tarde compará-los com novos textos, buscando avaliar o produto da estratégia de formação. Deve-se assinalar aqui quão difícil é conciliar os papéis de professora formadora e professora investigadora da formação!

Levando em conta a multiplicidade de saberes que emergiram nos textos iniciais das professoras, procuramos replanejar nossa ação didática. Tentamos selecionar textos de apoio bem variados, combinando alguns mais técnicos, com linguagem acadêmica, com outros menos formais, mais práticos e chegando até aos literários. Também tentamos variar as atividades, combinando algumas bem estruturadas, como, por exemplo, 
leitura e discussão dos textos técnicos, com outras bem informais, como, por exemplo, a leitura coletiva dos próprios diários. O conteúdo abordado nos seminários privilegiava tanto perspectivas bem amplas de conhecimento, de sociedade e de educação quanto conceitos mais específicos como avaliação, ensino e aprendizagem.

Usamos o diário reflexivo (Zabalza, 1994) como instrumento de registro das aprendizagens das professoras e como controle do nosso trabalho de formação. As professoras eram orientadas para, após cada encontro quinzenal, registrar suas aprendizagens. Em diferentes momentos do curso o conteúdo dos registros tornava-se objeto de análise.

Ao final do primeiro módulo (seis meses) as professoras foram convidadas a escrever um novo texto sobre o significado que atribuíam à avaliação.

$\mathrm{Na}$ análise de conteúdo desses textos ficou evidente a influência das leituras e das discussões feitas durante os seminários do primeiro módulo. Havia, mesmo, algumas professoras que repetiam quase literalmente as palavras dos autores estudados (Luckesi, 1995; Demo, 1995; Depresbíteris, 1993; Darsie, 1996), como por exemplo: "Avaliação é um processo sustentado e estratégico" (S7), que praticamente repete as palavras de Demo. De modo geral, o conteúdo dos textos evidencia:

\section{a) uma crítica à função exclusivamente classificatória da avaliação}

"Não serve apenas como um instrumento de medida rotulando os bons e maus alunos. Serve como instrumento de reflexão de nosso trabalho." (S9)

"Não é para taxar a capacidade e sim um mediador da evolução da aprendizagem." (S3)

"Algo para melhorar e não para classificar o aluno." (S13)

\section{b) ênfase no erro construtivo}

"Mostrar o erro e construir conhecimento." (S11)

"Compreendo mais os 'errinhos' dos alunos e consigo explicar melhor para eles aquele tipo de erro." (S2)

"Faz-me ver onde errei e onde tenho que corrigir." (S1)

\section{c) a avaliação como promotora de reflexão sobre o ensino e a aprendizagem}

"Eu vejo os problemas e mudo as estratégias para melhorar." (S7) 
"Ponto de apoio para nortear os trabalhos, as atividades de sala de aula ...repensar os conteúdos, seus valores na vida dos alunos, a realização do meu objetivo, como melhorar para tornar-me uma facilitadora da aprendizagem." (S10)

"É um meio de detectar o problema e mudar a estratégia para melhorar a aprendizagem e a qualidade do processo e da prática."

Além da clara influência dos autores lidos e discutidos em classe, fica também evidente, nos textos das professoras, novas maneiras de conceber o ensino e a aprendizagem. As professoras falam em troca de conhecimento: "Até agora eu tinha a concepção de que avaliar seria um meio de medir o conhecimento do aluno. Atualmente é uma troca de conhecimento e ajuda" (S15). Falam também em se tornar um mediador e um facilitador da aprendizagem: "A avaliação é o termômetro que mostrará qual é o método e conteúdo adequado para aquele aluno, e o professor deve ser mediador do aluno e desse saber novo que está sendo descoberto" (S19).

As mudanças já estariam ocorrendo ou seria apenas um resultado imediato do curso? Seria um efeito passageiro das leituras e discussões? $\mathrm{Ou}$ seria um desejo de impressionar as professoras formadoras?

O que nos levou a realizar essa atividade do registro ao final do primeiro módulo foi, mais uma vez, a preocupação com a pesquisa; buscava-se utilizar mecanismos de controle e sistematização do processo. Por que essa preocupação?

Nos trabalhos de pesquisa-ação ou de pesquisa colaborativa é bastante comum (e até compreensível) que toda a atenção fique concentrada na ação, deixando em segundo plano a pesquisa. No entanto, tratando-se realmente de um investigação, cabe verificar em que medida está-se conseguindo atender às exigências de um trabalho científico, ou seja: a) definição clara do objeto de estudo (o que se está querendo conhecer); b) fundamentação teórica para definir o problema e para analisar os dados (o que diz a literatura sobre formação docente, formação continuada, saberes profissionais); c) procedimentos bem definidos de controle do processo (quais os registros, quem os faz, em que situações, usando quais estratégias); d) procedimentos cuidadosos de sistematização dos dados (relatos provisórios, vinhetas narrativas, debates sobre os dados).

O diário reflexivo, como instrumento de registro das aprendizagens das professoras e como forma de acompanhar (avaliar) o trabalho de formação, mostrou-se mais adequado e eficiente, porque parece ter ficado menos contaminado por fatores como, por exemplo, o desejo de causar boa impressão à professora. 
A leitura dos textos produzidos após o primeiro módulo e a análise de seu conteúdo nos levou a pensar que seria necessário ter uma medida de mais longo prazo para ser comparada aos dados iniciais.

Mesmo assim, decidimos manter a coleta formal de opiniões das professoras acerca do andamento do processo para melhor atender às suas necessidades e para fazer os ajustes didáticos necessários. Ao final do segundo módulo (fim do primeiro ano), pedimos às professoras que fizessem uma avaliação escrita e bem livre do curso e dessem sugestões sobre a sua continuidade. Aproveitamos integralmente as sugestões feitas para montar as próximas etapas que consistiram, por um lado, na realização de oficinas, orientadas por especialistas de áreas específicas (matemática, geografia, ciências e linguagem), e, por outro, na organização de debates sobre tópicos como: disciplina/indisciplina, relação professor aluno e problemas gerais de educação.

O tom geral das apreciações feitas pelas professoras foi muito positivo, destacando principalmente a oportunidade que estavam tendo de refletir, de pensar novas formas de avaliação e de troca de experiências. Alguns exemplos:

"O curso foi muito importante, pois eu consegui parar e refletir a minha prática, acompanhar mais o processo de crescimento dos alunos, frear minha ansiedade em relação aos resultados e, principalmente, planejar novas ações para o próximo ano." (S17)

"Adorei fazer o curso, pois me deu uma outra concepção do processo de avaliação. Trocar experiências de cada um foi maravilhoso." (S8)

\section{ANÁLISE DAS CONCEPÇÕES DE AVALIAÇÃO AO FINAL DO PROCESSO}

Uma nova atividade de escrita do texto sobre a concepção de avaliação só ocorreu ao final de terceiro módulo, portanto após um ano e meio de trabalho. Nesse momento, as professoras foram convidadas a escrever um texto abordando o seguinte tema: "Eu, professora avaliadora".

$\mathrm{Na}$ análise de conteúdo desses textos podem ser destacados os seguintes aspectos:

\section{a) reconhecimento de que houve crescimento profissional}

"Já são quase 25 anos de trabalho como educadora; no início com medo, sem prática, inexperiente no convívio com crianças. À medida que foram se passando os anos, a habilidade foi sendo adquirida através de cursos, no contato com colegas, na troca de experiências, sempre tentando acertar, mas continuando com um trabalho 
empirista. A partir do curso 'Leitor crítico', a minha maneira de pensar/agir mudou, quase que radicalmente, com alunos, na maneira de avaliar, nos meus procedimentos, até particulares. Houve em mim um amadurecimento profissional que está me ajudando muito." (S7)

Nesse depoimento, a professora compara o antes e o depois do curso. Menciona que fazia um trabalho "empirista" e aqui ela se refere a um dos conteúdos tratados no curso, quando se discutiu as diferentes perspectivas da gênese do conhecimento. Mostra que a professora já incorporou o novo conceito, pelo menos em seu discurso.

Outra professora revela mudanças em seus sentimentos e emoções. Relembra que no início do curso sentia medo e insegurança e que foi positiva a troca de experiências com as colegas. Hoje se sente confiante e percebe que mudou a forma de olhar para os alunos.

"Fazendo uma retrospectiva desde quando ingressei no curso me lembro de quantas angústias, quantas dúvidas me rodeavam. Havia em mim muito medo de errar. Interessante foi perceber que os meus medos e inseguranças não eram só meus e sim de minhas colegas de curso. Que bom! Pudemos trocar grandes experiências...Hoje me transformei em uma profissional mais consciente, aprendi a olhar os meus alunos de forma diferente." (S9)

Uma outra professora também procura analisar as mudanças que percebe em seus conhecimentos, em sua prática, em seus alunos, em sua vida pessoal e profissional:

"Hoje avalio vários 'lados': meu lado profissional - estou mais consciente sobre como e porque realizar meu trabalho, e isso acontece mediante um tipo de avaliação que conscientiza; meu lado conhecimento - está evoluindo cada vez que paro para me avaliar, meu aprimoramento está se dando gradativamente e de modo maduro; meus alunos - estão tendo a chance de participar desse processo de avaliação comigo e dando muito de si para que esse processo seja efetivo; meu lado pessoal está feliz diante de mais uma conquista." (S5)

\section{b) possibilidade de reflexão sobre a própria prática}

"O trabalho que fizemos com o diário, aqui no PEC e depois com os alunos, foi muito gratificante, pôde nos mostrar um outro lado nosso que estava esquecido; o fato de registrar não só as emoções, mas também uma reflexão do nosso trabalho." (S11) 
A professora menciona os efeitos do curso nas suas concepções e na sua prática. Destaca o papel importante do diário no registro de suas reflexões.

Outra professora descreve seu processo de reflexão, seus questionamentos e mostra que mudou a sua forma de participação na escola.

"Hoje, sinto-me mais segura, acho que não tenho tantos desvios para chegar até um determinado objetivo. Penso sempre antes: por que? Para que? E onde quero chegar com aquela prática na sala de aula. Realmente reflito! Consigo argumentar, solucionar, sugerir, participar ativamente nas reuniões pedagógicas. Consegui até mudar muitos profissionais, mostrando outros caminhos." (S13)

Uma outra professora afirma que aprendeu a observar sua própria atuação docente com um olhar crítico, que aprendeu a "ver acima do dia-adia":

"Aprendi a observar minha atuação em sala de aula com maior clareza, aumentei a cobrança pessoal, que me impulsiona a procurar novos estímulos, a ver acima do dia-a-dia ...é muito válido fazermos o papel de críticos de nossa própria prática, fazermos uma parada para aprendermos a nos ver como profissionais. Ultrapassa a questão salarial, apesar de ser essa imensa, e torna-se uma questão de atualização profissional, o retomar das bases: o que faço, por que faço, como faço, como poderia fazer melhor. Assim vejo o curso 'Professor, leitor crítico de sua prática'." (S10)

\section{c) ampliação de horizontes quanto à educação e ao papel da escola}

"Depois de alguns meses fazendo este curso, pude observar que meu comportamento com relação a avaliar meus alunos mudou bastante, pois já não os vejo nem avalio da mesma forma que antes. Posso dizer que hoje levo em consideração muitas coisas que antes não achava ter importância. A relação do aluno com a família, as condições de vida precárias, muitas vezes vão para a escola sem comer nada, o sacrifício que muitos fazem para freqüentar a escola e ajudar nas despesas da casa, obviamente que não são todos, mas eu não tinha muita sensibilidade para observar nos meus alunos esses detalhes, que muitas vezes prejudicam o seu desempenho na escola." (S2)

O depoimento dessa professora revela que suas mudanças não ficaram restritas às concepções e práticas de avaliação, mas foram muito além, pois agora situa a avaliação numa perspectiva mais ampla e dispõe-se a considerar diversos fatores que afetam o desempenho escolar. 


\section{d) mudança nas relações de sala de aula e no desempenho dos alunos}

"Procurei aplicar tudo que ia vendo e aprendendo aqui, e os meus alunos foram tendo mais oportunidade de se expressarem livremente, falando o que pensavam e eu ia explicando o que era certo e errado, fazendo-os se corrigir. Essa autoavaliação fez com que eles avançassem na aprendizagem e eu me sentindo realizada ao ver no fim do ano que a minha maneira de ensinar teve sucesso." (S16)

O depoimento dessa professora mostra que ela passou a dar voz a seus alunos e a deixá-los escolher. Mostra, ainda, que essa nova forma de agir trouxe resultados positivos no final do ano.

Outra professora revela mudanças na concepção do erro, que a levaram a ver os alunos com outros olhos: "Vejo os alunos com outros olhos, onde o errar é humano, perdoável, aceitável, um fato a ser discutido, analisado" (S11).

\section{e) mudança nas práticas de avaliação}

“Eu, no começo, avaliava meus alunos só pela resposta da prova, que deveria estar igual à resposta do livro, mas de uns tempos para cá eu não faço mais isso. Primeiro leio a resposta e procuro interpretar o que o aluno respondeu e pondero a minha avaliação." (S6)

O depoimento dessa professora revela uma mudança na prática de avaliação que provavelmente advém de uma mudança em sua concepção do que significa ensinar e aprender: antes o certo estava fora, no livro. Agora ela considera o que vem do aluno, pensa e analisa.

$\mathrm{O}$ depoimento de uma outra professora mostra que ela passou a considerar mais os acertos, a evolução que o aluno teve:

"Como avaliadora do educando estou procurando, cada vez mais, os pontos de evolução em meus alunos. Onde ele conseguiu melhorar, o passo pra frente que deu ao invés de olhar só o que ele não conseguiu. Esse é o caminho: observar, elogiar, valorizar os pequenos progressos." (S10)

Diferentemente dos primeiros textos que eram muito curtos, esses textos eram, em geral, bastante longos, com conteúdo denso e ofereciam muitos elementos para avaliar a concepção da professora. Pôde-se observar uma mudança substantiva nas concepções de avaliação, mas também nas concepções de ensino, aprendizagem e de educação. 
O que os dados dessa pesquisa nos permitem concluir?

1) Que os saberes profissionais dos professores são plurais e heterogêneos; temporais; personalizados e situados; e humanos (Tardif, 2002).

2) Que a investigação-ação nos permite um estudo dos saberes profissionais dos professores tais como eles os utilizam e mobilizam nos diversos contextos do seu trabalho cotidiano.

3) Que é possível delinear um estratégia de formação continuada ancorada na concepção de professor como leitor crítico de sua prática.

\section{REFERÊNCIAS BIBLIOGRÁFICAS}

BARTHES, Roland. O Rumor da língua. Lisboa: Ed. 70, 1987. p. 284.

DARSIE, Marta M. Avaliação e aprendizagem. Cadernos de Pesquisa, n. 99, p. 47-59, nov. 1996.

DEMO, Pedro. Lógica e democracia da avaliação. Ensaio: avaliação e políticas públicas em educação. Rio de Janeiro, v. 3, n. 8, p. 323-330, 1995.

DEPRESBÍTERIS, Lea. Avaliação da aprendizagem: revendo conceitos e posições. In: SOUZA, C. P. S. (org.) Avaliação do rendimento escolar. Campinas: Papirus, 1993. p. 51-78.

GIMENO SACRISTÁN, J. Consciência e acção sobre a prática como libertação profissional dos professores. In: NÓVOA, A. (org.) Profissão Professor. Porto Editora, 1991. p.61-92.

LUCKESI, Cipriano C. Avaliação educacional escolar: para além do autoritarismo e Prática escolar: do erro como fonte de castigo ao erro como fonte de virtude. In: Avaliação da Aprendizagem Escolar. São Paulo: Cortez, 1995. p. 27-59.

NÓVOA, António. Formação de professores e profissão docente. In: p. 15-33. (org.) Os Professores e a sua formação. Lisboa: Dom Quixote, 1992. 
PÉREZ GÓMEZ, Angel. O Pensamento prático do professor: a formação do professor como profissional reflexivo. In: NÓVOA, A. (org.) Os Professores e a sua formação. Lisboa: Dom Quixote, 1992. p. 93-114.

PERRENOUD, P. Práticas pedagógicas, profissão docente e formação. Lisboa: Dom Quixote, 1993.

SCHÖN, Donald A. Formar professores como profissionais reflexivos. In: NÓVOA, A. (org.) Os Professores e a sua formação. Lisboa: Dom Quixote, 1992. p. 77-91.

TARDIF, Maurice. Saberes docentes e formação profissional. Petropólis: Vozes, 2002.

ZABALZA, Miguel Ángel. Diários de aula: contributo para o estudo dos dilemas práticos dos professores. Portugal: Porto Editora, 1994.

ZEICHNER, Ken. Novos caminhos para o practicum: uma perspectiva para os anos 90. In: NÓVOA, A. (org.) Os Professores e a sua formação. Lisboa: Dom Quixote, 1992. p. 115-138.

Recebido em: outubro 2004

Aprovado para publicação em: dezembro 2004 